\title{
GESTÃO DE DESIGN: CONTRIBUIÇÕES NO DESENVOLVIMENTO DE PRODUTOS EM EMPRESAS DE PRIVAT LABEL, SEGMENTO JEANSWEAR.
}

\author{
DESIGN MANAGEMENT: CONTRIBUTIONS IN PRODUCT DEVELOPMENT IN COMPANIES \\ PRIVAT LABEL, JEANSWEAR SEGMENT.
}

\begin{abstract}
GASPAR, Haylton Acácio; Especialista em Moda; Universidade Estadual de Londrina; acacio.haylton@gmail.com EMIDIO, Lucimar de Fátima Bilmaia; Mestre em Design; Universidade Estadual de Londrina; lucimaremidio@gmail.br NUNES, Valdirene Aparecida Vieira; Mestranda; PPG Design; UNESP - Universidade Estadual Paulista; Professora da Universidade Estadual de Londrina; valvieira01@yahoo.com.br
\end{abstract}

\begin{abstract}
Resumo: O presente trabalho aborda a importância da Gestão de Design de Moda na indústria de Privat Label do segmento de Jeanswear. Aponta, por meio de pesquisa bibliográfica e de um estudo de caso, as áreas em que a gestão do design abrange, destacando a importância do Gestor de Design nas empresas que atuam por meio da terceirização de serviços. Com a pesquisa espera-se colaborar de forma significativa na resolução dos problemas demandados pelas particularidades desta indústria aqui estudada, detectando o quanto é importante a atuação deste profissional com sua formação multidisciplinar e visão sistêmica no processo de desenvolvimento de produto e na linha de produção.
\end{abstract}

Palavras-chave: Gestão de Design; Privat label; Jeanswear; indústria.

Abstract: This paper discusses the importance of management in the Fashion Design Jeanswear segment Privat Label industry. Points, by means of literature and a case study, the areas where management covers the design, highlighting the importance of the Design Manager in companies that operate through outsourcing of services. With the research is expected to significantly collaborate in solving problems demanded by this industry characteristics studied here, detecting how important the performance of this professional training with a multidisciplinary and systemic view of the product development process and in the production line..

Keywords: Design management; Privat label; Jeanswear; industry. 


\section{1 - INTRODUÇÃO}

O mercado brasileiro de moda apresenta-se em ascensão, e apesar de todos os rótulos e críticas que a moda recebe, passou a ser visto como uma área de grandes oportunidades de negócios. A moda apresenta-se com um imenso complexo mundial que sempre se renova e, consequentemente, sempre se desenvolve. (CIDREIRA, 2005

A moda desperta o desejo e a necessidade de consumo. De acordo com Lipovetsky (1989), a lógica econômica realmente varreu todo ideal de permanência; é a regra do efêmero que governa a produção e o consumo dos objetos. A temporalidade curta da moda desencadeia um processo de renovação e de obsolescência "programada" propício a revigorar sempre mais o consumo e, com o design industrial, a moda não remete mais apenas aos caprichos dos consumidores, passando a ser uma estrutura constitutiva da produção industrial de massa.

A indústria textile é considerada a 5 a maior do mundo e a indústria de confecção nacional é a 4a maior e produz 6,5 bilhões de peças/ano (CNI, 2012). Durante muitos anos as empresas de confecção de marcas brasileiras tinham disponíveis dentro de suas próprias fábricas os seguintes profissionais: costureiras, modelistas, engenheiros de produção, técnicos e gerentes de lavanderia. No início da década de 1980, com o surgimento da Private Label ou PL, (empresas que prestam serviços especializas em áreas específicas), a visão de mercado se volta a estas, visando alcançar a rapidez e praticidade que estes grupos podem oferecer.

A expressão Privat Label, em inglês, significa etiqueta privada, é usada para nomear a prática das empresas que chegam a terceirizar $100 \%$ do processo produtivo composto pela: criação, modelagem, corte, montagem e acabamento das peças. Esse repasse total para outra empresa (também conhecida como facção industrial) acontece quando a contratada devolve o produto nos padrões exigidos e com a etiqueta do contratante.

Pode-se definir Private Label ou PL como uma operação pela qual marcas ou empresas transferem sua produção industrial para outras empresas confeccionistas fabricarem as peças sob encomenda" (ABRAL, 2010)

Diante desse contexto este trabalho aborda a importância da Gestão de Design de Moda na indústria de Privat Label, segmento de Jeanswear, apontando, por meio de pesquisa bibliográfica e de um estudo de caso, as áreas em que esta abrange, destacando a importância do profissional Gestor de Design, nas empresas que atuam com a terceirização de serviços.

\section{2 - INDÚSTRIA DE TERCEIRIZAÇÃO DE SERVIÇOS NO BRASIL}

O Brasil, antes da Primeira Guerra Mundial, já dispunha de um grande desenvolvimento na indústria têxtil. Durante esse período, foi protagonista do abastecimento de matéria-prima e produtos têxteis para os países envolvidos na guerra, após a qual os países europeus, junto dos Estados Unidos, se desenvolveram fortemente com a tecnologia industrial, consequentemente decaindo os lucros nacionais brasileiros. 
No início da década de 1930, com a chegada da crise nos países desenvolvidos, a indústria e o mercado nacional tiveram novamente grandes oportunidades de crescimento. Depois de longos anos o Brasil se via estagnado com o seu maquinário e desenvolvimento interno, porém o crescimento desenfreado do mercado de moda exigiu significativas alterações e reformulações na estrutura empresarial do mercado nacional.

Passamos a comprar equipamentos que também contemplavam a segurança do trabalhador, não apenas a segurança em si, mas também a poluição interna da fábrica, principalmente a poluição sonora, um dos principais problemas da indústria têxtil mais antiga. Os equipamentos não são tão barulhentos como antes. As fábricas tinham muito mais máquinas porque o processo de fabricação era mais longo. Hoje as máquinas são mais compactas e encurtam o processo. Para obter o mesmo quilo de fio no final, você tem menos máquinas que produzem muito mais. Também ocorreu diminuição de pessoas expostas ao processo fabril. Em 1990, havia pelo menos um milhão a mais de trabalhadores do que hoje (NAPOLI, 2007, p. 9)

Segundo Guimarães (1996) a terceirização da mão-de-obra no setor de confecção de vestuários a partir dos anos 80 vislumbrou-se com mais clareza, além de se tornar uma ferramenta estratégica para os empresários do ramo. Trata-se de uma prática operacional de sublocação bastante antiga que, além de reduzir ou eliminar desperdícios, proporciona uma melhor eficácia operacional, permitindo produtos de melhor qualidade a custos mais baixos.

A terceirização de serviço consiste em designar a terceiros, que possuem mão de obra e tecnologia especializada, a responsabilidade de confeccionar um produto com alta qualidade sem que haja riscos e custos. Uma vez iniciando esse trabalho a empresa não precisa se especializar em todos os processos e reduz os gastos internos, pois não haverá custo com aquisição de maquinário especifico, mão de obra, terceirização de serviços para finalização e manutenção. O sistema de terceirização propicia agilidade, pois a empresa contratada consegue efetuar a produção em massa com maior qualidade, uma vez que possui habilidade no produto fornecido.

A terceirização na visão de Silva (1997, p. 30) tem uma importância vital para determinadas empresas, pois:

... a transferência de atividades para fornecedores especializados, detentores de tecnologia própria e moderna, que tenha esta atividade terceirizada como sua atividade fim, liberando a tomadora para concentrar seus esforços gerenciais em seu negócio principal, preservando e evoluindo, em qualidade e produtividade, reduzindo custos e ganhando competitividade.

Já na opinião de Pagnani (1989) existem outras necessidades que as empresas buscam alcançar com a terceirização, ou seja, muitas dessas empresas além de almejarem a diminuição de riscos também buscam a diminuição dos custos trabalhistas e responsabilidades de gestão.

Atualmente, esse processo de trabalho gera anualmente milhões ao mercado de moda, pois as empresas inicialmente tinham interesses em focar apenas alguns 
produtos e, agora, conseguem distribuir a linha de produção para as empresas de terceirização, cujo serviço vai desde o desenvolvimento do produto até a entrega da mercadoria nos pontos de vendas. Por isso conseguem focar e investir nas áreas nas quais se tem maior domínio e facilidade.

Cabral (2004) apresenta alguns benefícios decorrentes da terceirização sob as seguintes perspectivas: econômica contábil, competências essenciais, eficiência operacional e custos de transação, conforme mostrado na Quadro 1, a seguir:

\begin{tabular}{|c|l|}
\hline Perspectivas & Fatores Estimuladores \\
\hline Econômica Contábil & $\begin{array}{l}\text { Transformação de custos fixos em variáveis; } \\
\text { Disponibilização de recursos financeiros. }\end{array}$ \\
\hline $\begin{array}{c}\text { Competências } \\
\text { essenciais }\end{array}$ & Foco sobre a atividade-fim da empresa. \\
\hline Eficiência & $\begin{array}{l}\text { Maior flexibilidade de produção; } \\
\text { Acesso às melhores tecnologias disponíveis. }\end{array}$ \\
\hline Custos de transação & $\begin{array}{l}\text { Melhor eficiência por meio da escolha da forma } \\
\text { organizacional adequada à redução dos custos de }\end{array}$ \\
\hline
\end{tabular}

Quadro 1 - Alguns benefícios decorrentes da terceirização.

Fonte: Cabral, 2004.

A terceirização de serviço possui um alto giro, pois a empresa proprietária da marca contratante solicita a manufatura do produto à empresa contratada, no caso a de Privat Label, inicia o processo de terceirização produzindo a mercadoria da marca contratante, porém não é responsável pela comercialização, seja ela bem-sucedida ou não, dos produtos que foram entregues.

\section{3 - GESTÃO DE DESIGN DE MODA}

A Gestão de Design teve início na Grã-Bretanha na década de 1960. O termo foi cunhado para se referir ao gerenciamento do relacionamento entre clientes. Nesse mesmo momento, nos Estados Unidos, Bill Hannon e o Massachusetts College of Art fundaram o Design Management Institute, em Boston, com o objetivo de treinar parceiros e gerentes designers como gestores e de desenvolver métodos para a relação da gestão em um ambiente empresarial. (MOZOTA, 2011, p. 92).

Burdek (2006) expõe que, na década de 1990, a Gestão de Design se transformou em uma competência intercultural, exigindo dos designers uma competência equivalente entre projeto e economia, além de competência relativa ao contexto, tanto no que se refere à cultura das empresas como dos grupos-alvo de consumidores. O papel especial do design, nessa conexão, é o de visualizar os respectivos conceitos e ilustrar as estratégias de produtos, produzindo "imagens" que se comuniquem de forma não verbal. 
A Gestão de Design é a organização das atividades de um design, delimitadas pela empresa com objetivo de implantar a cultura corporativa na mudança da sua própria imagem (FORNASIER, 2005). Ela surge a partir do desenvolvimento industrial do mercado, momento em que as empresas começam a sentir necessidade de criar diferenciais em relação aos concorrentes e passam, então, a executar ações que acrescentasse valor à sua imagem e inserir o design como elemento de competitividade.

Emidio ( 2006 ) aborda o contexto da indústria do vestuário de moda, que devido as especificidades dos seus produtos vê-se submetida às pressões competitivas para criar produtos inovadores e de qualidade, em prazos mínimos. Nesta área, observa a autora, trabalha-se constantemente, com o desenvolvimento de novos produto, tornando o ambiente extremamente favorável à utilização do design como uma alternativa que contempla a multidisciplinaridade e flexibilidade para atender as mudanças de gosto de consumidores, de forma acelerada e ininterrupta.

De acordo com a mesma, diante das pressões dos diferentes tipos de problemas, um dos grande desafios da área de moda é enfrentar os aspectos relacionados à sazonalidade, qualidade e preço do produto. Enfatiza-se, portanto, a necessidade de estratégias relacionadas com toda fase de desenvolvimento do produto, bem como as estratégias de design que atendam às principais demandas desta empresa. Assim, a atividade de design de produtos assume um papel de elevada importância nos processos de qualidades atuais, um papel estratégico, baseando-se no atendimento total ao cliente, em inovações a ritmo rápido e, na transformação dos sistemas de produção, aspectos que envolvem diretamente a integração dos processos de concepção e de produção para gerar novas soluções.

De acordo com Santos (2000) na abordagem estratégica, o processo de design se transforma no principal macroprocesso da organização, em que todos os esforços devem convergir de modo a ter-se um único objetivo: desenvolver, produzir e disponibilizar um produto de qualidade, conquistando e retendo clientes e ampliando a participação nos mercados.

Segundo Burdek (2006), a metodologia do design tem como meta, clara, esclarecer o processo de projeto e fornecer as ferramentas necessárias para sua otimização. Como observa Santos (2000), o processo de design enquanto agente responsável pelo desenvolvimento de produtos e, por consequência, da consolidação ou não da imagem da empresa no mercado, está presente em todas as atividades industriais necessárias para se produzir e vender um produto. Logo, o conceito de Gestão de Design incorpora o processo de design de produtos como um elemento funcional no planejamento estratégico da empresa.

O Gestor de Design de Moda possui um papel muito importante em todo o processo de desenvolvimento de produto e linha de produção. É fundamental que um gerente seja uma pessoa capacitada em design, pois poderá contribuir de forma significativa na resolução dos problemas. 


\section{4- PRIVAT LABEL: UM ESTUDO DE CASO NO SEGMENTO JEANSWEAR}

Apresenta-se a seguir um contexto vivenciado em uma empresa de $\mathrm{PL}$, do segmento de jeanswear, da cidade de Londrina, região norte do Estado do Paraná que estará denominada neste trabalho como empresa $X$. Trata-se de uma empresa consolidada no mercado de jeanswear especialista no processo de Privat Label, com 28 anos de atuação no mercado, onde possui uma infraestrutura de 100 mil metros quadrados de área total, sendo 15 mil metros de área construída, com 750 colaboradores e uma capacidade produtiva de 120 mil peças/mês.

O processo produtivo realizado na própria empresa compreende: a criação (pesquisa e desenvolvimento) modelagem, risco, corte, costura, lavanderia, tinturaria, estamparia, acabamento, bordado, expedição. A empresa terceiriza alguns tipos de processos diferenciados como bordado a laser, couro, lã, cordão e estamparia corrida.

O foco maior da empresa é a criação e o desenvolvimento de produto, pois visando atender as maiores marcas nacionais e internacionais atual a empresa $\mathrm{X}$ investe em pesquisa de tendência, que é realizada por meio de viagens internacionais nas principais capitais da Moda deste segmento: Berlin, Frankfurt, Tóquio, Barcelona, Paris e Londres. Nestas viagens buscam-se novidades, e produtos de marcas internacionais que são líderes no mercado, muitas peças são fotografadas e outras compradas para servirem como padrão de lavagem e modelos. Essas peças são utilizadas para apresentarem aos clientes como peças de pesquisas, juntamente com o mix de produtos em que a empresa $X$ produz para seguir com o seu showroom.

A empresa contratante passa seu esboço em formato de fichas técnicas, para a empresa X fazer o protótipo, denominado por eles como "peça piloto", que se aprovada pode resultar em pedido. Todo processo é analisado para evitar gargalos no decorrer do processo. No entanto, nesses esboços de fichas técnicas, muitas vezes não constam as informações básicas para o desenvolvimento deste produto, como tecido, cor e gramatura de linha, peso de jeans, processo de costura, dificultando o processo de trabalho da empresa $X$.

$O$ desenvolvimento do produto é de responsabilidade total da empresa $X$ que repassa todas as informações ao setor de modelagem, para que seja modelado conforme a tabela de medidas do cliente/ contratante.

O processo de costura possui o papel importante para a finalização do preço do produto, pois o cálculo do custo de mão-de-obra está relacionado ao tempo e quantidade de processos de costura feito em cada peça. Por isso, as peças cortadas são encaminhadas ao setor de pilotagem onde são analisadas, em conjunto com o profissionais modelista, designer e a pilotista, quais os processos de costura mais viáveis para linha de produção.

No departamento de pilotagem inicia-se o processo de costura da peça piloto, a após o produto ser costurado, a peça é novamente medida para que se possa tirar a média de encolhimento do tecido antes do processo de lavagem. A referida peça é encaminhado ao laboratório de lavanderia juntamente com o padrão de lavagem enviado pela contratante, que pode ser uma foto de uma peça em jeans lavado, peças importadas ou até mesmo uma receita de lavanderia industrial contendo as informações e "o passo-a-passo" de um novo processo de lavagem. 
Para a finalização do ciclo de produção da peça piloto inicial, na lavanderia, deve se passar por aprovação ou reprovação do produto pelo designer de moda, após este produto aprovado internamente é encaminhado para o departamento de modelagem, para novamente medir a peça já lavada , tira-se novamente a média de encolhimento deste tecido. Para finalizar o processo de produção da peça piloto é dado o acabamento no produto onde serão aplicados todos os insumos como: botões, rebites, etiqueta interna, etiqueta externa, tag e embalagem. Estes são aplicados após o processo de lavagem, pois se aplicados antes da lavagem industrial podem ser oxidados ou até destruídos.

Na sequência, a peça piloto é enviada à marca contratante do serviço para que esta possa ser analisada, medida e comparada com o padrão de lavagem. Uma vez que o produto seja aprovado, passa então para produção em série do mesmo, o qual não poderá sofrer nenhuma modificação, pois qualquer tipo de alteração afetará também os seus valores.

Ressalta-se que o processo de desenvolvimento de produto na indústria de Privat Label depende $100 \%$ de aprovação da empresa contratante. Muitas vezes a peça piloto não é aprovada para ser produzida devido ao alto custo ou devido a problemas de qualidade e de medidas, gerando um retrabalho e desgaste de ambas as partes.

\section{5- GESTÃO DE DESIGN DE MODA X PRIVAT LABEL: UMA ANÁLISE A PARTIR DO ESTUDO DE CASO}

Observa-se que no que se refere a indústria de jeanswear estudada, o profissional Designer de moda atua em três grandes áreas de alta complexidade, descritas a seguir:

Área de custos: onde o processo de desenvolvimento de produto deve analisar tempo para a produção do produto; processos produtivos e matéria-prima que sejam viáveis e com baixo valor de produção; itens responsáveis pelo preço final do produto, pois quanto maior for o tempo para ser produzido, matéria-prima e processos com alto grau de complexidade, maior será o valor agregado ao produto final;

Área de criação, desenvolvimento e produtiva: processos operacionais facilitadores relacionados a linha de produção, analisando o maquinário e mão-de-obra disponível, para que não haja a redução do fluxo operacional da empresa. Uma vez que toda linha de produção seja feita internamente, sem que haja a terceirização de serviços por falta de maquinário ou mão-de-obra, o valor e a qualidade do produto conseguem se estabilizar.

Área de relacionamento: responsável pelo feedback entre a empresa de Privat Label e a da marca contratante dos produtos.

Assim, Gestão de Design de Moda na empresa de Privat Label é exercida obedecendo as fases do processo produtivo mostrado na Figura 1, abaixo. 


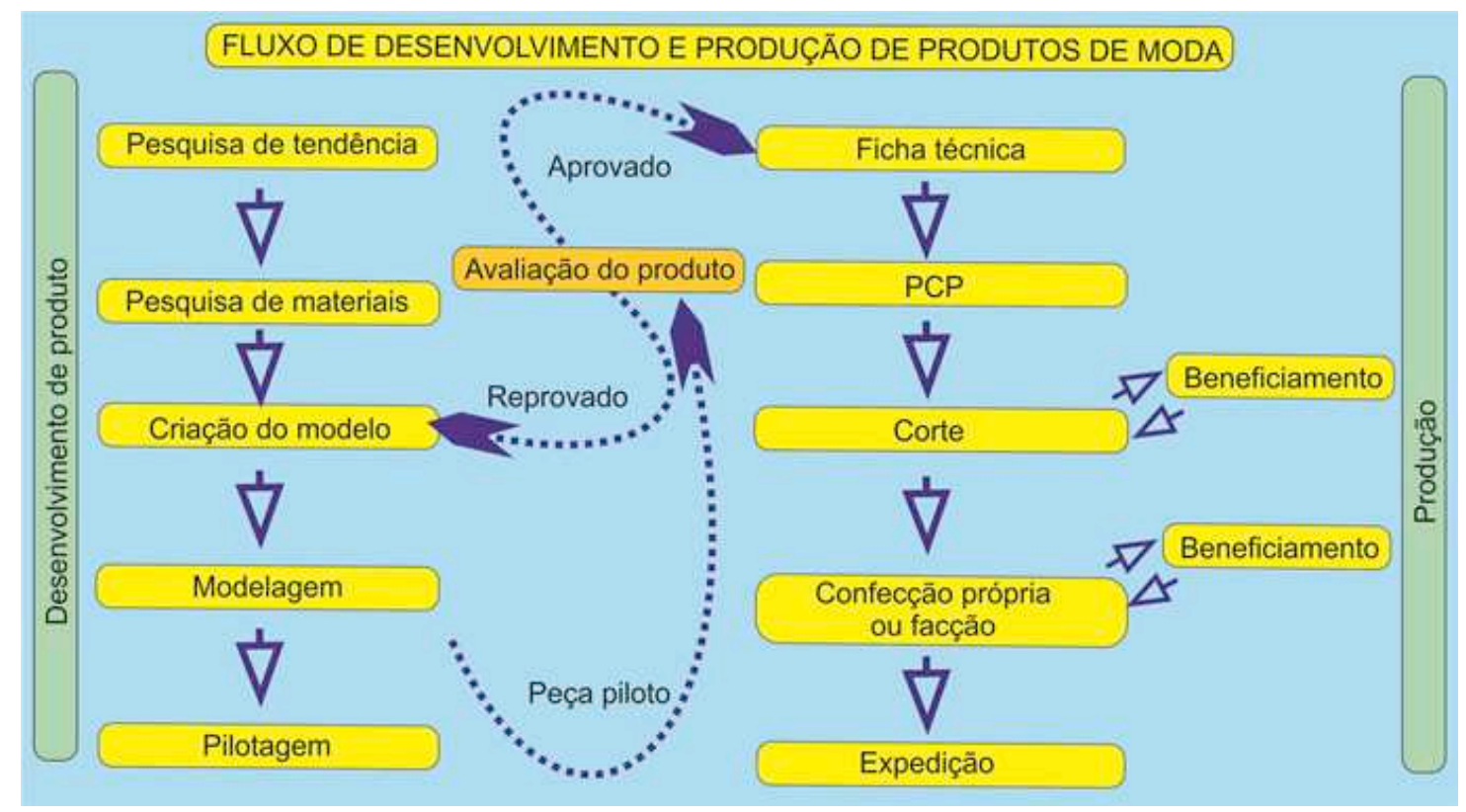

Figura 2: Fases do processo produtivo Fonte: Mendes (2010, pag. 194 )

Os maiores problemas que gerem retrabalhos nas empresas de Privat Label são oriundos da ausência ou de erros das informações repassadas pelas empresas contratantes, pois toda e qualquer informação precisa estar descrita e corretamente na ficha técnica do produto, que segundo Souza (2006), é um referencial para integração dos ofícios de concepção e confecção do modelo, o principal veículo de comunicação entre o criador e o profissional modelista na indústria, logo:

\begin{abstract}
"a ficha técnica deve conter toda a memória descritiva do produto" e para que esta seja elaborada todos os dados têm que ser de conhecimento e estar disponível ao profissional envolvido, e este tem que fornecer uma ficha clara, concisa, dotada de toda a informação necessária, respeitando a quem irá lê-la." (LEITE E VELLOSO, 2006, P.147)
\end{abstract}

Para Mendes (2010, pag. 42), "a etapa de desenvolvimento do produto, absorve um tempo maior do fluxo total e é o período de grande experimento até a aprovação de todas as características do produto."

Assim, infere-se que o acompanhamento do Gestor de Design é essencial para a desenvolvimento e o crescimento da empresa, pois tal profissional com um grau de qualificação conseguirá identificar possíveis problemas que sejam facilmente alterados e corrigidos. Na indústria de jeans estudada, a Gestão de Design torna-se muito mais influente, pois trabalha diretamente com a criação, desenvolvimento do produto e a linha de produção em série, onde qualquer decisão afetará esteticamente o produto final.

O produto e o desenvolvimento do mesmo devem basear-se no preço determinado pelo contratante, sendo tarefa do gestor de moda conseguir enquadrar, preço, qualidade, lavanderia, linha de produção e estética em um produto para ser produzido a baixo custo. 
Desta forma, o Gestor de Design de Moda que atua em empresas de Privat Label, precisa estar instruído sobre todo o processo fabril da empresa, uma vez que os resultados da criação e o do desenvolvimento dos produtos neste tipo de empresa, dependerá totalmente do maquinário, linha de produção e serviços terceirizados disponíveis, ou seja este profissional trabalhará adequando- se ao que está disponível para sua atuação.

\section{6 - CONSIDERAÇÕES FINAIS}

Conforme observado, na busca pela diferenciação e inovação, as empresas se encaixam em diversas modalidades de formatação de negócios, e no que se refere ao contexto de empresas de Privat Label, é importante salientar que os profissionais designers de moda que desejam atuar nestas, necessitam inicialmente especializar-se também no chamado "Chão-de-Fábrica", pois, o processo de criação necessita estar atrelado paralelamente com as informações coerentes à linha de produção, uma vez o produto em processo de desenvolvimento, precisará estar correlacionado com todo o conjunto que o envolve.

A partir dos estudos realizados neste trabalho, destaca-se que um dos maiores problemas causadores de gargalos no processo de desenvolvimento do produtos em empresas de Privat Label, esta relacionada à falta de informações, planejamento e acompanhamento contínuo, ou seja de gestão do processo. Salienta-se portanto, a importância da atuação de um profissional com formação multidisciplinar e visão sistêmica do processo, como o Gestor de Design, para que possa contribuir para a interligação do desenvolvimento do produto à linha de produção, sempre analisando meios e processos mais viáveis para que os produtos possam ser executados da forma coerente. Entende-se que processo produtivo mal administrado pode acarretar problemas futuros como retrabalhos e falhas nas sequências operacionais, resultando perdas substanciais para empresa.

Outra questão observada, neste perfil de empresa é o aproveitamento de peças e modelos, devido a grande semelhança de materiais, lavagens, e detalhes entre as marcas, é comum uma marca contratante obter "peças piloto" muito próximas ou idênticas à outras empresas concorrentes. Sendo a moda complexa, efêmera, uma área que exige ritmo constante de trabalho cabe ao designer o desafio de projetar produtos, a partir de uma visão ética de sua área de atuação.

\section{REFERÊNCIAS}

Associação Brasileira de Licenciamento- http://abral.org.br/a-abral/ » http://www.cea.com.br/saladeimprensa/ca-e-mattel-celebram-parceria. Acesso em: 03/2014.

BURDEK, Bernhard E. História, teoria e prática do design de produtos. Trad. Freddy Van Camp. São Paulo: Blücher, 2006.

CABRAL, Sandro. Analisando a reconfiguração da cadeia de produção de pneus no Brasil pela economia dos custos de transação. Rev. Gestão e Produção, v. 11, n.3, p. 373-384, set/dez. 2004. 
CIDREIRA, Renata Pitombo. Os Sentidos da moda: vestuário, comunicação e cultura .São Paulo: Annablume, 2005.

CNI - Confederação Nacional da Indústria. Têxtil e confecção: inovar, desenvolver e sustentar. Junho, 2012. Disponível em: <http://www.cni.org.br/portal/data/pages/FF80808137E2BEF7013801108D4A479D.ht m>. Acesso em: 3 dez. 2013.

EMIDIO, Lucimar de Fátima Bilmaia. A gestão do design como ferramenta estratégica para MPES do vestuário de moda : Um estudo de caso na região de Londrina. Bauru, 2006. Dissertação (Mestrado em Desenho Industrial) - Universidade Estadual Paulista.

EMÍDIO, Lucimar de Fátima Bilmaia. Modelo de diagnóstico para checagem de utilização do design por MPES de vestuário de moda: Uma ferramenta para estudo de caso. In: MARTIS, Roseane Fonseca de Freitas ( Org. ). Pelos caminhos do Design : Metodologia de projeto 2012.

GUIMARÃES, E. A. A experiência recente da política industrial no Brasil: uma avaliação. Brasília, IPEA - Texto para discussão n 409, 1996.

LEITE, A. S.; VELLOSO, M. D. Desenho técnico de roupa feminina. Rio de Janeiro: Senac Nacional, 2006.

LIPOVETSKY, G. O império do efêmero: a moda e seu destino nas sociedades modernas. São Paulo: Companhia das Letras, 1989.

MENDES, Francisca Dantas. Rede de empresas : A cadeia têxtil e as estratégias de manufatura na indústria brasileira do vestuário de moda. São Paulo : Arte \& Ciência 2010.

MOZOTA, Brigitte Borja de. Gestão do design: usando o design para construir valor de marca e inovação corporativa. Porto Alegre: Bookman, 2011.

PAGNANI, E. M. A subcontratação na pequena e média empresa. Campinas: Editora da UNICAMP, 1989.

SANTOS, Flávio Anthero dos, 1971. O Design como diferencial competitivo. Itajaí:

Univali, 2000.

SILVA, C. P. da. A terceirização responsável: modernidade e modismo. São Paulo: LTR Editora, 1997.

SOUZA, Patrícia de Mello. A modelagem tridimensional como implemento do processo de desenvolvimento do produto de moda. Bauru, 2006. $113 \mathrm{f}$. Dissertação (Mestrado em Desenho Industrial) - Universidade Estadual Paulista. 